\title{
Drug Therapy in Patients With Chronic Renal Failure
}

\author{
by Bertram Hartmann, David Czock, and Frieder Keller
}

\section{SUMMARY}

Background: Roughly $20 \%$ of patients in hospital have impaired kidney function. This is frequently overlooked because of the creatinine-blind range in which early stages of renal failure are often hidden. Chronic kidney disease is divided into 5 stages (CKD 1 to 5 ).

\section{Methods: Selective literature search.}

Results: Methotrexate, enoxaparin and metformin are examples of drugs that should no longer be prescribed if the glomerular filtration rate (GFR) is $60 \mathrm{~mL} / \mathrm{min}$ or less. With antidiabetic (e.g. glibenclamide), cardiovascular (e.g. atenolol) or anticonvulsive (e.g. gabapentin) drugs, the advice is to use alternative preparations such as gliquidone, metoprolol or carbamazepine which are independent of kidney function. Drug dose adjustment should be considered with antimicrobial (e.g. ampicillin, cefazolin), antiviral (e.g. aciclovir, oseltamivir) and, most recently, also for half of all chemotherapeutic and cytotoxic drugs in patients with impaired kidney function (with e.g. cisplatin, for instance, but not with paclitaxel).

Conclusion: Decisions concerning drug dose adjustment must be based on the pharmacokinetics but this is an adequate prerequisite only in conjunction with the pharmacodynamics. There are two different dose adjustment rules: proportional dose reduction according to Luzius Dettli, and the half dosage rule according to Calvin Kunin. The latter leads to higher trough concentrations but is probably more efficient for anti-infective therapy.

Cite this as: Dtsch Arztebl Int 2010; 107(37): 647-56 DOl: 10.3238/arztebl.2010.0647

Universität Ulm, Medizinische Fakultät, Nephrologie: Dr. med. Hartmann, Prof. Dr. med. Keller

Universitätsklinikum Heidelberg, Abteilung Klinische Pharmakologie und

Pharmakoepidemiologie: PD Dr. med. Czock
$\mathrm{C}$ hronic kidney disease (CKD) is divided into five stages; thus, the global term "compensated renal insufficiency" should no longer be used (Table 1). It is important to know whether a patient is suffering from renal insufficiency (CKD stages 2 through 5) and, if so, at what stage, because roughly half of all drugs or their metabolites are excreted by the kidneys, and 30\% of all adverse effects of medication have either a renal cause or a renal effect (1).

As estimated in the NHANES study, the prevalence of renal insufficiency with a glomerular filtration rate (GFR) under $60 \mathrm{~mL} / \mathrm{min}$ is $11 \%$ to $13 \%$ (e1). Some $20 \%$ of all hospitalized patients have impaired renal function. The "creatinine-blind range" corresponds to a GFR value between 120 and $60 \mathrm{~mL} / \mathrm{min}$. In persons over age 65, a GFR that is lower than it was, but still above $60 \mathrm{~mL} / \mathrm{min}$ (CKD stage 1 or 2), may well reflect a decline in renal function as part of normal aging.

The Modification of Diet in Renal Disease (MDRD) formula is used, in a reversal of the usual logic, to infer an independent variable, the glomerular filtration rate (GFR), from a dependent variable, the serum creatinine level (SCrea mg/dL). The classic MDRD2 formula has had to be modified for recently recalibrated measurements of the creatinine level (e1). According to this formula, the GFR (in $\mathrm{mL} / \mathrm{min}$ per $1.73 \mathrm{~m}^{2}$ of body surface area [BSA]) depends mainly on the patient's age, but also on his or her skin color and sex: "white" and "male" are both assigned coefficients of 1.0, while "black" is assigned a coefficient of 1.212 and "female" a coefficient of 0.742 .

$$
\text { MDRD_GFR }=175.6 \cdot \text { SCrea }^{-1.154} \cdot \text { age }^{-0.203} \cdot 0.742(\text { female }) \cdot 1.212(\text { black })
$$

The MDRD-GFR can also be used to adjust drug doses in the setting of renal insufficiency (2), but, when this is done, the calculation must include an estimate of

\section{Prevalence}

The prevalence of renal insufficiency with a glomerular filtration rate (GFR) below $60 \mathrm{~mL}$ / min was estimated at $11 \%$ to $13 \%$ in the NHANES study. 


\section{TABLE}

The severity of renal insufficiency and stages of chronic kidney disease (CKD) with additional findings such as microalbuminuria ${ }^{*}$

\begin{tabular}{l|l|l} 
CKD Stage & GFR $(\mathrm{mL} / \mathrm{min})$ & $\begin{array}{l}\text { Renal } \\
\text { insufficiency }\end{array}$ \\
\hline 1 & $120-90$ & none \\
\hline 2 & $90-60$ & mild \\
\hline 3 & $60-30$ & intermediate \\
\hline 4 & $30-15$ & severe \\
\hline 5 & $15-0$ & $\begin{array}{l}\text { preterminal, } \\
\text { requires dialysis }\end{array}$ \\
\hline & & $*^{1}$ modified from (e15)
\end{tabular}

the patient's BSA, for example, with the Mosteller formula (3) (www.halls.md/body-surface-area/bsa.htm).

$$
B S A=\frac{\sqrt{\text { height }(\mathrm{cm}) \cdot \text { weight }(\mathrm{kg})}}{60}
$$

\section{Learning objectives}

The purpose of this article is to demonstrate that, in renal insufficiency,

- certain drugs are particularly useful, and

- in principle, any drug can be given to any patient, as long as the dose is adjusted in accordance with the relevant pharmacokinetics and pharmacodynamics.

\section{Special aspects of pharmacotherapy in renal insufficiency}

If the GFR is below $60 \mathrm{~mL} / \mathrm{min}$, i.e., if the patient is in CKD stage 3 or higher, certain drugs should no longer be given, either because they tend to damage the kidneys or because they are insufficiently eliminated by poorly functioning kidneys and will therefore accumulate in the body and cause toxic side effects on other organs (4). Radiological contrast media containing iodine should be given to patients with renal insufficiency only after prophylactic hydration. In order to prevent contrast-medium toxicity, the authors additionally give $1600 \mathrm{mg}$ of MESNA (methoxyethylsulfonate sodium) in $500 \mathrm{~mL}$ of normal saline $0.9 \%$ intravenously immediately before and during the contrast study (5). In
CKD stage 4 and above, magnetic resonance imaging with gadolinium is no longer a risk-free alternative to iodinated media. In these stages of CKD, gadolinium preparations (linear ones more often than cyclic ones) can cause a serious condition known as nephrogenic systemic fibrosis. Thus, if the GFR is under $30 \mathrm{~mL} /$ min, gadolinium should be eliminated from the body with hemodialysis immediately after the MRI study (6).

ACE inhibitors, $\mathrm{AT}_{1}$ blockers, and the renin inhibitor aliskiren have renally dependent pharmacokinetics, so that it suffices to give these drugs in half the normal dose to patients with renal insufficiency. In this situation, special attention must be paid to the risk of hyperkalemia. To avoid hyperkalemia, spironolactone should be given only in a low dose (no higher than 25 $\mathrm{mg} /$ day), or not at all, to patients with renal insufficiency; if it is given, then only in combination with a thiazide diuretic, furosemide, or both.

As there are some drugs that exert their effects independently of renal function, it is often useful to search for one of these drugs as a clinical alternative (Table 2). Cefepime should not be given from CKD stage 4 onward, i.e., when the GFR is below $30 \mathrm{~mL} / \mathrm{min}$, because there have been eight reported cases of lethal central nervous system intoxication occurring after five to seven days of parenteral treatment in dialysisdependent patients (7). Drugs that should not, in general, be given to patients in CKD stage 3 or higher (GFR under $60 \mathrm{~mL} / \mathrm{min}$ ) include methotrexate, enoxaparin, metformin, and lithium (Table 3).

Methotrexate and enoxaparin accumulate in a deep compartment. After four to eight weeks of use, methotrexate can cause long-lasting bone marrow toxicity (8). With enoxaparin (unlike tinzaparin), eight days of treatment-even if the dose is adjusted to the GFR — can lead to hemorrhagic complications, which become more likely each day that the drug is given (9). Lithium is excreted through the kidneys and can induce toxic effects such as athetosis, renal diabetes insipidus, and renal failure (10); therefore, its use in CKD 3 or higher requires expert management (e2). The example of lithium also reminds us, however, that the discontinuation of a drug is always fraught with risk and must always be discussed with the prescribing physician (a psychiatrist, in this particular case). Once all the risks have been taken into consideration, it may turn out to be best to continue giving a nephrotoxic medication despite a low GFR.

\section{Radiological contrast media}

Patients with renal insufficiency should undergo prophylactic hydration before they are given radiological contrast media that contain iodine.

\section{Gadolinium}

Linear gadolinium preparations can bring about the clinical picture of nephrogenic systemic fibrosis when given to patients in CKD stage 4 or higher. 
Metformin is considered to be an insulin sensitizer, and there is a current trend toward increasing use of this drug. Although lactic acidosis is a rare complication of metformin, and is even rarer when the dose is reduced (500 mg b.i.d.), it remains highly lethal when it occurs (11). As the patient's renal function may be unstable, patients whose GFR is under $60 \mathrm{~mL} / \mathrm{min}$ should be treated with less dangerous alternative drugs, such as the DPP-IV inhibitor sitagliptin (Table 2), whose dose should be halved if the GFR is under $30 \mathrm{~mL} / \mathrm{min}$. Half of therapeutically administered insulin is metabolized in the renal parenchyma (e3); thus, in renal insufficiency, the insulin effect often lasts longer, so that the patient needs less insulin overall. It is a common scenario for a diabetic patient to be admitted to hospital with hypoglycemia as the result of a worsening of renal function.

For patients whose GFR is below $60 \mathrm{~mL} / \mathrm{min}$, the proper use of analgesics remains an important issue. In the authors' view, combined analgesic preparations are contraindicated in patients with renal insufficiency, as they may cause dependency. The kidneys' major “enemies” are now the nonsteroidal anti-inflammatory drugs (NSAIDs), such as diclofenac, iboprofen, and indomethacin, and the selective COX-2 inhibitors, which should only be given with monitoring of the serum creatinine level. In patients with preexisting renal damage, the use of NSAIDs can lead to further, permanent renal damage (12). The opioid drug pethidine should not be given to patients with renal insufficiency, because its renal-dependent metabolite, normeperidine, can cause cerebral convulsions (Table 3). Morphine can be given with clinical follow-up at short intervals, but the necessary dose of morphine is lower in the setting of renal insufficiency, and the physician must be aware that respiratory depression can arise in delayed fashion, after a few days of treatment, because of a gradual accumulation of the active metabolite M6-glucuronide. Fentanyl and levomethadone may be advantageous, as these drugs have no active metabolites and are independent of the GFR.

\section{The treatment of comorbidity in CKD}

The treatment of comorbidity in patients with chronic renal insufficiency becomes an important issue no later than when CKD stage 4 is reached, with a GDR below $30 \mathrm{~mL} / \mathrm{min}$. The evidence grade and recommendation strength for the various treatment options can be derived from Cochrane Reviews and published metaanalyses (Table 4).

\section{TABLE 2}

Drugs that do and do not depend on renal function (e2)

\begin{tabular}{|c|c|c|}
\hline Class & $\begin{array}{l}\text { Dependent on renal } \\
\text { function }\end{array}$ & $\begin{array}{l}\text { Independent of renal } \\
\text { function }\end{array}$ \\
\hline Analgesics & $\begin{array}{l}\text { Morphine (M6-glucuro- } \\
\text { nide), pethidine } \\
\text { (norpethidine) }\end{array}$ & $\begin{array}{l}\text { Fentanyl, } \\
\text { levomethadone }\end{array}$ \\
\hline Antiarrhythmic drugs & Sotalol & Amiodarone \\
\hline Antibiotics & Ciprofloxacin, levofloxacin & Moxifloxacin \\
\hline \multirow[t]{3}{*}{ Antidiabetic drugs } & $\begin{array}{l}\text { Glibenclamide, glimepride } \\
\text { (hydroxy metabolite) }\end{array}$ & Gliquidone, gliclacide \\
\hline & Nateglinide & Pioglitazone \\
\hline & Sitagliptine & \\
\hline Anticonvulsants & $\begin{array}{l}\text { Gabapentin, pregabalin, } \\
\text { lamotrigine, levetiracetam }\end{array}$ & $\begin{array}{l}\text { Carbamazepine, } \\
\text { phenytoin, valproate }\end{array}$ \\
\hline Antihypertensive drugs & Atenolol & $\begin{array}{l}\text { Bisoprolol, carvedilol, } \\
\text { metoprolol, propranolol }\end{array}$ \\
\hline Cholesterol-lowering drugs & Bezafibrate, fenofibrate & Simvastatin, niacin \\
\hline $\begin{array}{l}\text { Drugs for gout and other } \\
\text { rheumatological conditions }\end{array}$ & Methotrexate & $\begin{array}{l}\text { Colchicine, } \\
\text { hydroxychloroquine, } \\
\text { leflunomide }\end{array}$ \\
\hline Cardiovascular drugs & Digoxin & Digitoxin \\
\hline Psychoactive drugs & Lithium, mirtazapine & $\begin{array}{l}\text { Amitriptyline, citalopram } \\
\text { (metabolites?), } \\
\text { haloperidol, risperidone }\end{array}$ \\
\hline Antiviral drugs & Acyclovir & Brivudine \\
\hline Cytostatic drugs (20) & $\begin{array}{l}\text { Actinomycin D, } \\
\text { bleomycin, capecitabine, } \\
\text { carboplatin, cisplatin, } \\
\text { cyclophosphamide, } \\
\text { doxorubicin, epirubicin, } \\
\text { etoposide, gemcitabine } \\
\text { (dFdU), ifosfamide, } \\
\text { irinotecan, melphalan, } \\
\text { methotrexate, oxaliplatin, } \\
\text { topotecan }\end{array}$ & $\begin{array}{l}\text { Anastrozole, docetaxel, } \\
\text { doxorubicin-peg-liposomal, } \\
\text { erlotinib, fluorouracil, } \\
\text { gefitinib, leuprorelin, } \\
\text { megestrol, paclitaxel, } \\
\text { tamoxifen, terozol, } \\
\text { vincristine, trastuzumab }\end{array}$ \\
\hline
\end{tabular}

Because renal insufficiency is associated with sodium retention (13), diuretic treatment is usually necessary; for this purpose, the best strategy is usually sequential nephron blockade with furosemide and hydrochlorothiazide.

The TREAT, CREATE, and CHOIR studies have shown that, in pre-dialysis patients, high-dose treatment with drugs that are intended to stimulate erythropoiesis can lead to strokes or tumor progression without protecting the kidneys (e4-e6). Therefore, the new

\section{The kidney's main "enemies" are:}

- Nonsteroidal anti-inflammatory drugs (NSAIDs) such as diclofenac, ibuprofen, and indomethacin - Selective COX-2 inhibitors

\section{Opioids}

The opioid drug pethidine should not be given to patients with renal insufficiency, because its renal-dependent metabolite, normeperidine, can cause cerebral convulsions. 


\section{TABLE 3}

The most important drugs whose use in patients with renal insufficiency is absolutely or relatively contraindicated or problematic from a clinical nephrological standpoint ${ }^{*}$

\begin{tabular}{|c|c|c|c|}
\hline Class & Drug & $\begin{array}{l}\text { Contraindicated or } \\
\text { to be avoided if } \\
\text { possible when: }\end{array}$ & Reason \\
\hline Analgesics & Pethidine & GFR $<60$ & Convulsions \\
\hline Antibiotics & Cefepime & GFR $<30$ & CNS toxicity \\
\hline $\begin{array}{l}\text { Phase-prophylactic } \\
\text { psychotropic drugs }\end{array}$ & Lithium & GFR $<60$ & $\begin{array}{l}\text { Nephro- and } \\
\text { neurotoxicity }\end{array}$ \\
\hline \multirow[t]{2}{*}{ Antidiabetic drugs } & $\begin{array}{l}\text { Glibenclamide, } \\
\text { gimepiride }\end{array}$ & GFR $<60$ & Hypoglycemia \\
\hline & Metformin & GFR $<60$ & Lactic acidosis \\
\hline Diuretics & $\begin{array}{l}\text { Spironolactone, } \\
\text { eplerenone }\end{array}$ & GFR $<30$ & Hyperkalemia \\
\hline $\begin{array}{l}\text { Immune } \\
\text { suppressants }\end{array}$ & Methotrexate & GFR $<60$ & Myelotoxicity \\
\hline $\begin{array}{l}\text { Radiological } \\
\text { contrast media }\end{array}$ & Gadolinium & GFR $<30$ & $\begin{array}{l}\text { Nephrogenic } \\
\text { systemic fibrosis }\end{array}$ \\
\hline LMW-heparin & Enoxaparin & GFR $<60$ & Risk of hemorrhage \\
\hline
\end{tabular}

\section{TABLE 4}

Evidence levels (from $1=$ high to $5=$ low) and recommendation strengths (from $\mathrm{A}=$ strong to $\mathrm{C}=$ weak) for the treatment of comorbidity in chronic renal insufficiency ${ }^{* 1}$

\begin{tabular}{l|l|l|l} 
Condition & Treatment & $\begin{array}{l}\text { Evidence level } \\
\text { and recommendation } \\
\text { strength }\end{array}$ & References \\
\hline Sodium retention & Diuretics & $3 \mathrm{~A}$ & $(13, \mathrm{e} 17)$ \\
\hline $\begin{array}{l}\text { Target } \mathrm{Hb} 10 \text { rather than } \\
12-13 \text { g/dL }\end{array}$ & Epo & $1 \mathrm{~A}$ & $\begin{array}{l}(14, \mathrm{e} 4-\mathrm{e} 6, \\
\mathrm{e} 18)\end{array}$ \\
\hline Inadequate iron resorption & Iron IV & $1 \mathrm{~A}$ & $(15, \mathrm{e} 19)$ \\
\hline 1a-hydroxylase deficiency & Calcitriol & $2 \mathrm{C}$ & $(16, \mathrm{e} 20)$ \\
\hline Hyperparathyroidism & Paricalcitol & $3 \mathrm{C}$ & $(\mathrm{e} 7, \mathrm{e} 20)$ \\
\hline Hyperparathyroidism & Cinacalcet & $1 \mathrm{~B}$ & $(\mathrm{e} 7, \mathrm{e} 21)$ \\
\hline Neutralization of acidosis & Bicarbonate & $3 \mathrm{~B}$ & $(17, \mathrm{e} 22)$ \\
\hline $\mathrm{Ca} \times \mathrm{PO}_{4}$-product & Sevelamer & $2 \mathrm{~B}$ & $(\mathrm{e} 7, \mathrm{e} 23)$ \\
\hline $\mathrm{Ca} \times \mathrm{PO}_{4}$-product & Lanthanum & $3 \mathrm{C}$ & $(\mathrm{e} 7, \mathrm{e} 23)$
\end{tabular}

${ }^{* 1}$ Some of the Cochrane Reviews and Cochrane Meta-Analyses cited (e18, e20, e22) do not consider the more recent studies (e4-e6, 16, 17) recommendation is for a target hemoglobin value of 10 $\mathrm{mg} / \mathrm{dL}$ (14). Before an erythropoietic hormone is given, iron should be given first. Iron is poorly taken up by patients with renal insufficiency when given orally, because of the elevated hepcidin level (15); it is thus best to give iron IV.

Large-scale observational studies have revealed that the additional administration of active vitamin D (e.g., calcitriol) in the predialysis phase is associated with lower mortality (16). It is important to monitor the calcium level and the calcium-phosphate product ( $\mathrm{Ca} \times$ $\mathrm{PO}_{4}$ ). Paricalcitol and cinacalcet should remain in reserve for the treatment of severe, clinically manifest hyperparathyroidism. Oral neutralization of acidosis with bicarbonate in the predialysis phase protects the bones, lessens malnutrition, and slows the progressive loss of renal function (17). A stepwise algorithm for the use of phosphate binders has been published (e7): The treatment begins with calcium acetate. If this is ineffective or poorly tolerated, sevelamer (or the newly available sevelamer carbonate) should be given instead as a powder. The authors use lanthanum and phosphate binders containing aluminum only for short times, and only in otherwise intractable cases.

\section{Pharmakokinetics}

Calvin Kunin, in the 1950's, carried out the first systematic study of the prolongation of drug half-lives in the setting of progressively severe renal insufficiency (e8). Drugs for which this is true are excreted more slowly than normal and can, therefore, accumulate to toxic levels if given repeatedly. The dosage of these drugs must be adjusted according to the patient's degree of renal insufficiency. Not only is every patient different, every drug is different as well. Nonetheless, there are simple rules of pharmacokinetics and pharmacodynamics that apply to every drug and every patient. With the aid of these rules, the dosage of any drug can be adjusted for any patient.

Friedrich Hartmut Dost described long ago the practical advantages of using a drug's half-life $\left(T_{1 / 2}\right)$ rather than its clearance (e9). The dominant half-life is the most important part of the concentration time curve with respect to the drug's exerting its intended, primary effect (Luzius Dettli). The renally eliminated fraction of a drug $\left(f_{\text {ren }}\right)$ is the key to predicting its pharmacokinetics in patients with renal insufficiency. For healthy subjects, $f_{\text {ren }}$ is calculated from the quantity of drug eliminated in the urine $\left(\mathrm{M}_{\text {urine }}\right)$ and the dose after
Problematic drugs whose use in patients with renal insufficiency is nephrologically contraindicated:

Pethidine, cefepime, lithium, gilbenclamide, gimepiride, metformin, spironolactone, eplerenone, methotrexate, gadolinium, enoxaparin.

\section{Pharmacokinetics}

The renally eliminated fraction of a drug is a key to predicting its pharmacokinetics in patients with renal insufficiency. 
intravenous administration (D), or else from the halflife of the drug in patients with normal $\left(\mathrm{T}_{1 / 2 \mathrm{norm}}\right)$ and failing $\left(\mathrm{T}_{1 / 2 \text { fail }}\right)$ renal function.

$$
f_{\text {ren }}=\frac{M_{\text {urine }}}{D}=1-\frac{T_{1 / 2 \text { norm }}}{T_{1 / 2 \text { fail }}}
$$

Luzius Dettli (e10) had the innovative idea of correlating the elimination rate constant, which is inversely proportional to the half-life $\left(\mathrm{k}_{\mathrm{e}}=0.693 / \mathrm{T}_{1 / 2}\right)$, linearly with renal function (Figure 1). To estimate the expected half-life of a drug based on the patient's individual GFR, we need to know the two extreme values of the half-life ( $T_{1 / 2 \text { norm }}$ und $T_{1 / 2 \text { fail }}$ ), which, in turn, tell us what fraction of the drug is normally eliminated renally $\left(f_{\text {ren }}\right)$ :

$$
T_{1 / 2}=\frac{T_{1 / 2 \text { norm }}}{1-f_{\text {ren }} \cdot\left(1-\frac{G F R}{G F R_{\text {norm }}}\right)}
$$

The renally eliminated fraction can also be derived from its counterpart, the non-renally eliminated fraction $\mathrm{Q}_{0}\left(\mathrm{f}_{\mathrm{ren}}=1-\mathrm{Q}_{0}\right)$, and can be obtained online on the “dosing” website (www.dosing.de). Like the serum creatinine level, the half-life has a hyperbolic dependence on renal function (Figure 2). There is a range of noncritical values for the half-life when the GFR is above $60 \mathrm{~mL} / \mathrm{min}$; this is analogous to the creatinine-blind range (18).

\section{Dose adjustment}

Many drugs must have their doses adjusted to renal function in patients with CKD stage 3 or higher, i.e., GFR lower than $60 \mathrm{~mL} / \mathrm{min}$. In the absence of dose adjustment, aciclovir and valaciclovir can be neurotoxic, ganciclovir and valganciclovir myelotoxic, foscavir nephrotoxic, and cidofovir both myelo- and nephrotoxic. Dose adjustment has proved to be outstandingly useful for these vitally indicated drugs. Further drugs whose doses need to be adjusted are oseltamivir, which is effective against the H1N1 virus, and intravenous zanamivir.

Drugs for which dose adjustment is often forgotten include the newer antiepileptic drugs, such as gabapentin (19), pregabalin, lamotrigine, and levetiracetam. For these drugs, half the normal dose or an even smaller amount will often suffice (Table 2).

\section{Dose adjustment}

For patients in CKD stage 3 or above whose GFR is below $60 \mathrm{~mL} / \mathrm{min}$, the dose of many drugs must be adjusted in accordance with renal function.

\section{FIGURE 1}

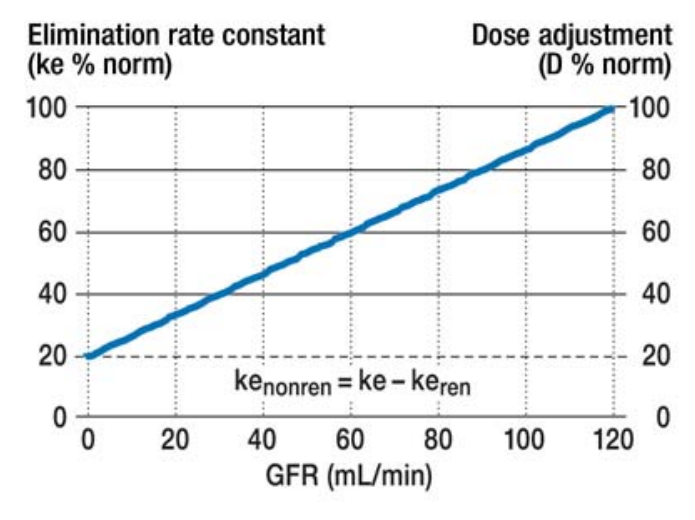

Drug elimination and renal function. According to Luzius Dettli, the elimination rate constant $\left(\mathrm{ke}=0.693 / \mathrm{T}_{1 / 2}\right)$ depends linearly on the glomerular filtration rate (GFR) (e10). The non-renal elimination rate constant $\left(\mathrm{ke}_{\text {nonren }}\right)$ is calculated as the difference of the normal and renal elimination rate constants $\left(\mathrm{ke}_{\text {nonren }}=\mathrm{ke}-\mathrm{ke}_{\text {ren }}\right)$. The drug dose (D) is adjusted to renal function proportionally to the elimination rate constant, and therefore inversely proportionally to the half-life (e10). D \% norm, dose change expressed as a percentage of the normal dose

\section{FIGURE 2}

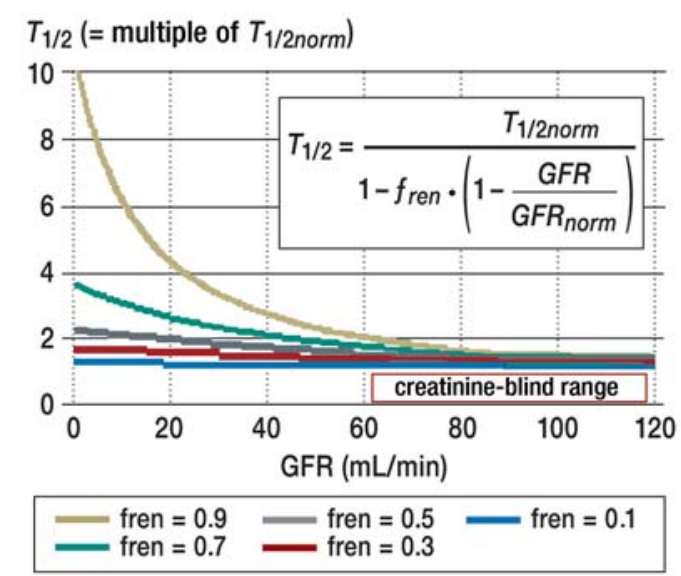

Half-life and renal function. The half-life $\left(T_{1 / 2}\right)$ depends in hyperbolic fashion on the glomerular filtration rate (GFR). The dependence is stronger with a higher renal elimination fraction $\left(f_{\text {ren }}\right)$. There is, however, a range of non-critical values for the half-life when the GFR is above $60 \mathrm{~mL} / \mathrm{min}$; this is analogous to the creatinine-blind range (18)

\section{Cytostatic agents that depend on renal function}

When a drug of this type is given to a dialysis patient, its dose must be reduced to $40 \%$ to $80 \%$ of the standard dose. 
FIGURE 3

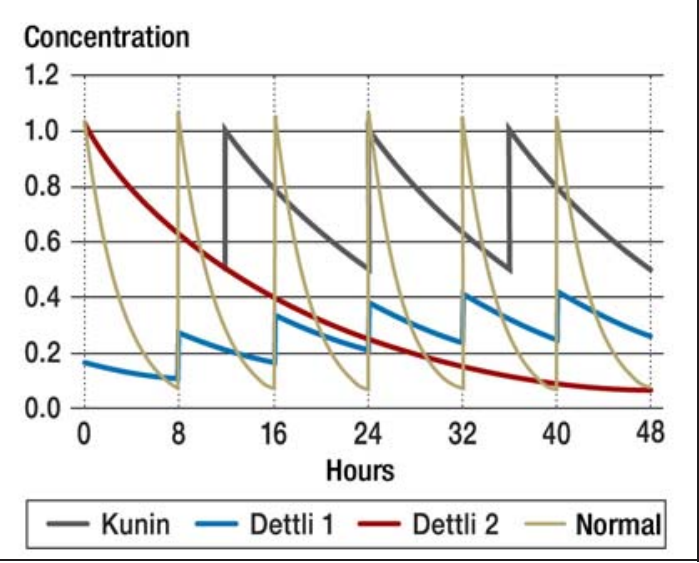

Dose adjustment in renal insufficiency (e16). The Kunin rule (e12) with halving of the starting dose leads to higher trough values and more frequent peak values than the Dettli-2 rule with the same dose given at longer intervals (e10). The Dettli-1 rule, with a reduced dose and a constant interval, results in lower peaks and higher troughs than normal (e10)

More and more commonly, cancer patients with renal insufficiency undergo treatment with cytostatic and other chemotherapeutic drugs. It is helpful to distinguish cytostatic agents that depend on, or are independent of, renal function (20). Those that depend on renal function must be given to dialysis patients in $40 \%$ to $80 \%$ of the standard dose (21). Those that are independent of renal function do not require dose adjustment for renal function, but rather for the patient's general condition. Unlike the authors of an article on this topic that was published in 2007 (20), the authors of the current article consider gemcitabin to depend on renal function because of its active metabolite dFdU (Table 2). The dose of gemcitabin, platinum derivatives, or of cyclophosphamide need not be lowered if the patient undergoes hemodialysis on three consecutive days, one to twelve hours after the administration of either of these dialyzable drugs. For carboplatin and cisplatin, dialysis must begin one to two hours after the infusion in order to be effective. Etoposide and epirubicin are not dialyzable.

Cumulation kinetics implies that there are separate considerations for the starting dose and the maintenance dose, as Augsberger already pointed out with respect to the digitalis glycosides (e11). If the effect of the drug must have a rapid onset, then the treatment should begin with a normal starting dose, so that an effective drug concentration can be established at once. With antibiotics, in particular, one should never commit the capital error of forgetting the starting dose. One always begins with the normal dose as the starting dose; only the maintenance dose is adjusted to the patient's renal function, as reflected by the drug's half-life.

The second innovative idea of Luzius Dettli was to realize (e10) that the necessary dose adjustment could be calculated proportionally to the changed elimination rate (and thus inversely proportionally to the half-life) (Figure 1). Either the dose (D) of a drug must be reduced in inverse proportion to the half-life $\mathrm{T}_{1 / 2}$ (the Dettli-1 rule), or else the interval (Tau) between doses must be prolonged proportionally to the half-life $T_{1 / 2}$ (the Dettli-2 rule). These two rules can also be applied in combination.

$$
\frac{D}{\text { Tau }}=\frac{D_{\text {norm }}}{\text { Tau }_{\text {norm }}} \cdot \frac{T_{1 / 2 \text { norm }}}{T_{1 / 2}}
$$

If, for example, the half-life of a drug is five times longer because of renal insufficiency, its dose should be reduced to $20 \%$ of the normal dose $(1 / 5=0.20)$. If the dose is thus reciprocally lowered and the interval between doses is unchanged, then the area under the curve will be the same as in the normal case, but with higher trough values (Figure 3), which are what is customarily measured in drug monitoring. This can easily lead physicians unfamiliar with the relevant pharmacokinetics to draw false conclusions and then reduce the dose of the drug still further, e.g., in the case of vancomycin or gentamicin. In order to achieve effective levels in patients with renal failure, the trough values of vancomycin should lie between 10 and $15 \mathrm{mg} / \mathrm{L}$, and those of gentamicin between 2 and $4 \mathrm{mg} / \mathrm{L}$.

Dettli's proportionality rule often implies the administration of absurdly low doses, or much too wide intervals between doses, in patients with renal failure who are under treatment in intensive care units. In the case of ampicillin, for example, one would have to reduce the dose of ampicillin from $1000 \mathrm{mg}$ every 8 hours to 100 mg every 8 hours, or perhaps 1000 mg every 80 hours. This illustrates the importance of a second dosing rule, the halving rule of Calvin Kunin (e12), which generally yields higher doses than Dettli's rule and thus seems to provide severely ill patients with a higher chance of effective treatment (Figure 3). This rule

\section{Starting dose and maintenance dose of antibiotics}

It should not be forgotten that patients with renal insufficiency need a higher starting dose! Begin with the normal dose. The maintenance dose is adjusted to renal function depending on its half-life.

\section{The halving rule of Kunin}

If the half-life is shorter than the dosing interval, dose adjustment is usually unnecessary. 
states that the starting dose should be the same as the normal dose ( $D_{\text {start }}$ equals $\left.D_{\text {norm }}\right)$, and thereafter half the starting dose should be given at intervals equal to one half-life (Tau equals $T_{1 / 2}$ ). The main benefit of this scheme is to achieve effective peak levels.

$$
\frac{D}{\text { Tau }}=\frac{1 / 2 \cdot D_{\text {start }}}{T_{1 / 2}}
$$

Kunin's halving rule makes it immediately clear that patients with life-threatening conditions generally do not need dose adjustment when the half-life of a drug is shorter than the dosing interval.

The halving rule results in peak drug levels that are the same as those in patients with normal renal function, but markedly higher trough levels; the area under the curve is greater than with the Dettli rule (Figure 3). This larger area under the curve can, however, be associated with more frequent adverse effects. The authors prefer to use the Kunin rule in the intensive care unit for pharmacodynamic reasons (4), and we have published corresponding dosing recommendations in tabular form (www.uni-ulm.de/nephrologie). Underdosing of antibiotics, in comparison to overdosing, can have much worse, indeed potentially fatal effects.

The importance of pharmacodynamics also becomes clear in the use of loop diuretics such as furosemide and torasemide. Starting in CKD stage 5, i.e., when the GFR is $15 \mathrm{~mL} / \mathrm{min}$ or less, these drugs must be given in higher rather than lower doses to be effective.

\section{Pharmacodynamics}

Dose adjustment is a question not just of pharmacokinetics, but also of pharmacodynamics, i.e., of the effect that one intends to achieve. Pharmacodynamics involves a formulation of the relationship between the concentration of a drug and its effect, most commonly described in terms of the so-called sigmoid $\mathrm{E}_{\max }$ model. In this mode, the effect is a non-linear function of the concentration of the drug at its site of action (C) and of the concentration that produces a half-maximal effect $\left(\mathrm{CE}_{50}\right)$. The parameter $\mathrm{E}_{\max }$ is associated with the maximal effect, and the Hill coefficient $\mathrm{H}$ describes the degree of sigmoidicity ("S-shapedness") of the relationship. When the Hill coefficient $H$ equals 1 , the $E_{\text {max }}$ model yields the Michaelis-Menten equation.

$$
E=\frac{E_{\max }}{1+\left(C E_{50} / C\right)^{H}}
$$

\section{Pharmacodynamics}

The therapeutically effective target range of a drug depends on the Hill coefficient.

\section{FIGURE 4}

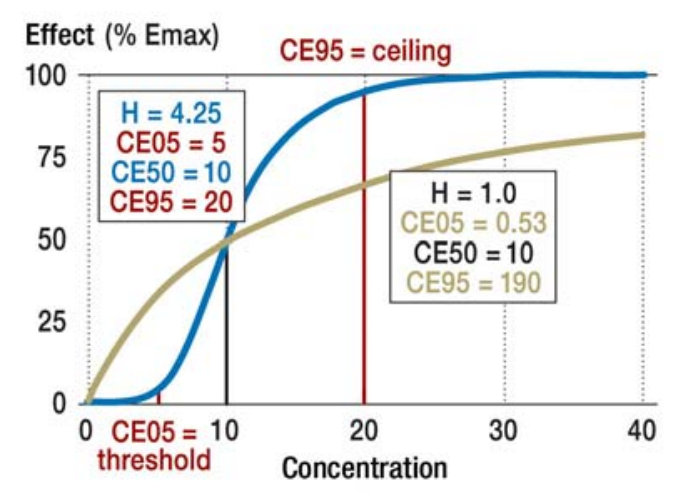

The examples of furosemide and torasemide show that pharmacodynamic parameters can also change in renal insufficiency. The required concentration of these drugs to achieve a half-maximal effect becomes higher in renal insufficiency $\left(\mathrm{CE}_{50 f a i l}>\mathrm{CE}_{50 \text { norm }}\right)$ : both must often be dosed 10 times higher in order to achieve an adequate diuretic effect.

The sigmoid $\mathrm{E}_{\max }$ model (Figure 4) involves the definition of a threshold concentration $\mathrm{CE}_{05}$ (18) at which only $5 \%$ of the maximal effect is achieved $\left(E_{05}\right.$ equals $\left.0.05 \times \mathrm{E}_{\max }\right)$.

$$
C E_{05}=C E_{50} \cdot 19^{\frac{-1}{H}}
$$

Similarly, the so-called ceiling concentration $\mathrm{CE}_{95}$ is that at which $95 \%$ of the maximal effect is achieved ( $\mathrm{E}_{95}$ equals $\left.0.95 \times \mathrm{E}_{\max }\right)$.

$$
C E_{95}=C E_{50} \cdot 19^{\frac{1}{H}}
$$

For a Hill coefficient of 1.0, the threshold concentration is only $1_{1 / 1}$ of that which produces a half-maximal effect, while the ceiling concentration is 19 times as high as that which produces a half-maximal effect (Figure 4). On the other hand, when the Hill coefficient equals 4.25 (for example), the threshold concentration is half that which produces a half-maximal effect, and the ceiling concentration is only twice the concentration that produces a half-maximal effect (Figure 4). The therapeutically effective range of a drug thus depends on its Hill coefficient: the higher the Hill
Sigmoid effectconcentration curve. The higher the Hill coefficient $(H>1.5)$, the closer the threshold concentration $\left(\mathrm{CE}_{05}\right)$ and the ceiling concentration $\left(\mathrm{CE}_{95}\right)$ lie to the concentration with half-maximal effect $\left(\mathrm{CE}_{50}\right)$.

\section{Antibiotic effect}

Antibiotics whose effect depends on their concentration have a low Hill coefficient $(H<1.5)$, while antibiotics whose effect is time-dependent have a high Hill coefficient $(\mathrm{H}>1.5)$. 
FIGURE 5

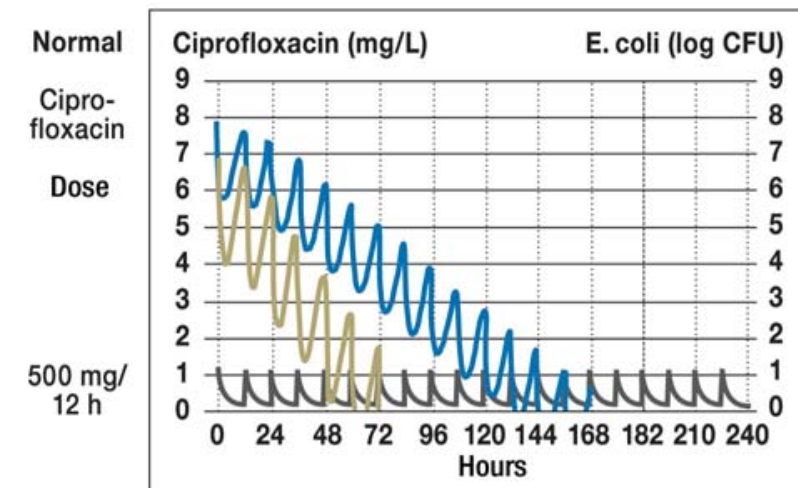

$12 \mathrm{~h}$

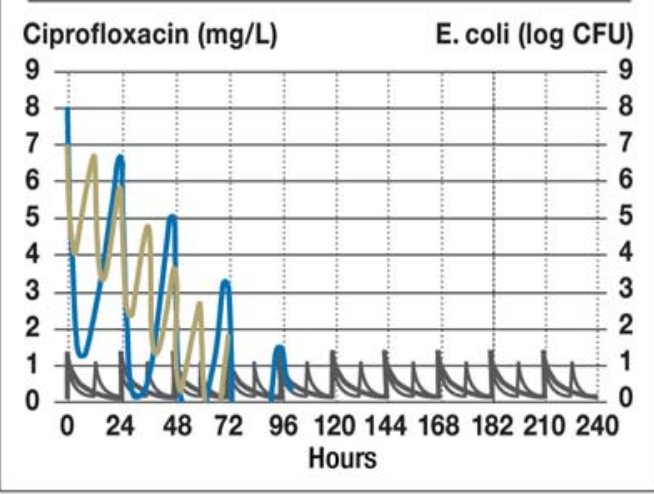

physician often does not know the value of $\mathrm{CE}_{95}$ or $\mathrm{CE}_{50}$ with any precision. Beta-lactams, such as cefazolin, and antiviral drugs, such as valganciclovir, are examples of antibiotics whose effect is time-dependent and for which the concentration should not become any lower than the threshold concentration $\mathrm{CE}_{05}$. These two classes of antibiotics, distinguished by the concentration- or time-dependency of their effects, differ in the height of their Hill coefficients (Figure 4): antibiotics of the former type have a low Hill coefficient $(\mathrm{H}<1.5)$, while those of the latter type have a high Hill coefficient ( $\mathrm{H}>1.5)$ (22).

The starting dose is important for both types of antibiotic, those whose effect is concentration-dependent and those whose effect is time-dependent. After the starting dose is given, the important consideration for antibiotics of the former type is the drug concentration at the beginning of each dosing interval, while that for the latter type is the drug concentration at the end of each dosing interval. Thus, for drugs of the former type, such as ciprofloxacin or levofloxacin, there is less reason to reduce the dose (23); it would seem to be better to prolong the interval between doses for patients with renal insufficiency, while keeping the individual dose the same as usual (Figure 5). Further examples of drugs of this pharmacodynamic type are cytostatic agents such as cyclophosphamide, melphalan, and daunoblastin (18). For cytostatic agents with a narrow therapeutic window, careful consideration of pharmacodynamics is needed, because adverse effects may be correlated with the area under the curve and might arise even after the administration of a single dose.

On the other hand, for antibiotics whose effect depends on time, such as ceftazidime (a beta-lactam) and the virustatic agents, it is less important to achieve peak levels that are well above $\mathrm{CE}_{50}$, but it is absolutely necessary to ensure that the trough level at the end of each dosing interval does not drop below $\mathrm{CE}_{05}$, as this might lead to loss of the antimicrobial effect. It follows that a continuous infusion might be a better administration strategy for beta-lactams, as has been shown in the case of oxacillin (24). The same consideration often applies in antiviral HIV therapy: the trough levels must not drop below the therapeutically effective concentration, as this will allow the pathogen to replicate, leading to the danger that resistance will develop (25). For antibiotics whose effect depends on time, such as cefotaxime or aciclovir, it makes more sense to lower the dose rather than prolong the interval between doses, as is done in the case of ciprofloxacin or daptomycin.

\section{Conclusion}

In the field of gerontopharmacology, one often hears the principle "Start low, go slow," which was formulated by Jerry Gurwitz and applies mainly to drugs that exert an effect in the central nervous system (e13). On the other hand, there is a much older principle that has been, to some extent, forgotten over the years: "Go fast, start high"-in the original German, "Sofort und hoch dosieren,” as stated by Paul Ehrlich in 1913 with regard 
to anti-infective therapy (e14). This remains an important principle in nephropharmacology today, particularly for antibiotics and antiviral drugs, but also for oncological cytostatic drugs. “Go fast, start high” applies not only in the intensive care unit, but also in general medical practice. Above all, one must not make the mistake of dosing anti-infective or cytostatic drugs too low at the start, or of forgetting the starting dose entirely. This mistake should be avoided in all patients, including those with renal insufficiency.

\section{Conflict of interest statement}

Dr. Hartmann and Professor Keller state that they have received payment of travel expenses and research support from Wyeth and Novartis. PD Dr. Czock states that he has no conflict of interest as defined by the guidelines of the International Committee of Medical Journal Editors.

\section{Manuscript submitted on 6 April 2010, revised version accepted on 5 July} 2010

Translated from the original German by Ethan Taub, M.D.

\section{REFERENCES}

1. Corsonello A, Pedone C, Corica F, et al.: Concealed renal insufficiency and adverse drug reactions in elderly hospitalized patients. Arch Intern Med 2005; 165: 790-5

2. Stevens LA, Nolin TD, Richardson MM, et al: Chronic Kidney Disease Epidemiology Collaboration. Comparison of drug dosing recommendations based on measured GFR and kidney function estimating equations. Am J Kidney Dis 2009; 54: 33-42.

3. Czock D, Bertsche T, Haefeli WE: Drug dose adjustments in patients with renal impairment. Am J Kidney Dis 2009; 54: 983-4.

4. Keller F: Nephrotoxische Störungen und nierenabhängige Arzneimittel. In: Risler T, Kühn K (eds.): Facharzt Nephrologie. München: Urban \& Fischer 2008: 891-960.

5. Ludwig U, Riedel MK, Backes M, Imhof A, Muche R, Keller F: MESNA (Sodium 2-Mercaptoethanesulfonate) for prevention of contrast medium-induced nephrotoxicity. Clin Nephrol 2010 (in press).

6. Kielstein JT, Schiffer M: Nephrogenic systemic fibrosis: a rare disease with grave consequences. Internist 2010; 51: 39-44.

7. Sonck J, Laureys G, Verbeelen D: The neurotoxicity and safety of treatment with cefepime in patients with renal failure. Nephrol Dial Transplant 2008; 23: 966-70.

8. Karie S, Gandjbakhch F, Janus N, et al.: Kidney disease in RA patients: prevalence and implication on RA-related drugs management: the MATRIX study. Rheumatology 2008; 47: 350-4.

9. Mahé I, Aghassarian M, Drouet L, et al.: Tinzaparin and enoxaparin given at prophylactic dose for eight days in medical elderly patients with impaired renal function: a comparative pharmacokinetic study. Thromb Haemost 2007; 97: 581-6.

10. Bendz H, Schön S, Attman PO, Aurell M: Renal failure occurs in chronic lithium treatment but is uncommon. Kidney Int 2010; 77: 219-24.

11. Almirall J, Bricullé M, Gonzalez-Clemente JM: Metformin-associated lactic acidosis in type 2 diabetes mellitus: incidence and presentation in common clinical practice. Nephrol Dial Transplant 2008; 23: 2436-8.

12. Schwarz A, Krause PH, Kunzendorf U, Keller F, Distler A: The outcome of acute interstitial nephritis: risk factors for the transition from acute to chronic interstitial nephritis. Clin Nephrol 2000; 54: 179-90.

13. Salem MM: Pathophysiology of hypertension in renal failure. Semin Nephrol. 2002: 22: 17-26.

14. Singh AK: Does TREAT give the boot to ESAs in the treatment of CKD anemia? J Am Soc Nephrol 2010; 21: 2-6.

15. Cui Y, Wu Q, Zhou Y: Iron-refractory iron deficiency anemia: new molecular mechanisms. Kidney Int 2009; 76: 1137-41.

16. Shoben AB, Rudser KD, de Boer $H$, Young B, Kestenbaum B: Association of oral calcitriol with improved survival in nondialyzed CKD. J Am Soc Nephrol 2008; 19: 1613-9.

17. De Brito-Ashurst I, Varagunam M, Raftery MJ, Yaqoob MM: Bicarbonate supplementation slows progression of CKD and improves nutritional status. J Am Soc Nephrol 2009; 20: 2075-84.

18. Aymanns C, Keller F, Maus S, Hartmann B, Czock D: Review on pharmacokinetics and pharmacodynamics and the aging kidney. Clin J Am Soc Nephrol. 2010; 5: 314-327.
19. Onuigbo MA, Nye D, lloanya PC: Drug-induced encephalopathy secondary to non renal dosing of common medications in two dialysis patients. Adv Perit Dial 2009; 25: 89-91.

20. Li YF, Fu S, Hu W et al.: Systemic anticancer therapy in gynecological cance patients with renal dysfunction. Int J Gynecol Cancer 2007; 17: 739-63.

21. Boesler B, Czock D, Keller F et al: : Clinical course of haemodialysis patients with malignancies and dose-adjusted chemotherapy. Nephrol Dial Transplant 2005; 20: 1187-91.

22. Czock D, Keller F: Mechanism-based pharmacokinetic-pharmacodynamic modeling of antimicrobial drug effects. J Pharmacokinet Pharmacodyn 2007; 34: 727-51.

23. Czock D, Rasche FM: Dose adjustment of ciprofloxacin in renal failure: reduce the dose or prolong the administration interval? Eur J Med Res 2005; 10: $145-8$.

24. Hughes DW, Frei CR, Maxwell PR et al.: Continuous versus intermittent infusion of oxacillin for treatment of infective endocarditis caused by methicillinsusceptible Staphylococcus aureus. Antimicrob Agents Chemother 2009; 53: 2014-9.

25. Czock D, Markert C, Hartman B, Keller F: Pharmacokinetics and pharmacodynamics of antimicrobial drugs. Expert Opin Drug Metab Toxicol 2009; 5 : 475-87.

\section{Corresponding autho}

Prof. Dr. med. Frieder Keller

Section Nephrologie

Klinik für Innere Medizin I

Zentrum für Innere Medizin

Universitätsklinikum Ulm

Albert-Einstein-Allee 23

89081 Ulm, Germany

For eReferences please refer to:

www.aerzteblatt-international.de/ref3710

Case illustration available at:

www.aerzteblatt-international.de/10m0647

\section{FURTHER INFORMATION ON GME}

This article has been certified by the North Rhine Academy for Postgraduate and Continuing Medical Education.

Deutsches Ärzteblatt provides certified continuing medical education (CME) in accordance with the requirements of the Medical Associations of the German federal states (Länder). CME points of the Medical Associations can be acquired only through the Internet, not by mail or fax, by the use of the German version of the CME questionnaire within 6 weeks of publication of the article. See the following website: cme.aerzteblatt.de

Participants in the CME program can manage their CME points with their 15-digit "uniform CME number" (einheitliche Fortbildungsnummer, EFN). The EFN must be entered in the appropriate field in the cme.aerzteblatt.de website under "meine Daten" ("my data"), or upon registration. The EFN appears on each participant's CME certificate.

The solutions to the following questions will be published in issue 45/2010.

The CME unit "The Post-Mortem External Examination" (issue 33/2010) can be accessed until 2 October 2010.

For issue 41/2010 we plan to offer the topic "Dyslexia: Diagnosis, Treatment, and Prevention."

Solutions to the CME questionnaire in issue 28-29/2010:

Vogel M et al.: The Treatment of Patients With HIV.

1b, 2b, 3d, 4e, 5c, 6b, 7c, 8a, 9d, 10a 
Question 1

Chronic renal insufficiency is divided into how many CKD stages?
a) One
b) Two
c) Three
d) Four
e) Five

\section{Question 2}

According to epidemiological studies, what is the prevalence of renal insufficiency with a GFR below $60 \mathrm{~mL} / \mathrm{min}$ ?
a) $5-10 \%$
b) $10-15 \%$
c) $15-20 \%$
d) $20-25 \%$
e) $25-30 \%$

Question 3

With what glomerular filtration rate does it usually become necessary to adjust drug doses to renal function?
a) GFR $<15 \mathrm{~mL} / \mathrm{min}$
b) GFR $<30 \mathrm{~mL} / \mathrm{min}$
c) $\mathrm{GFR}<60 \mathrm{~mL} / \mathrm{min}$
d) GFR $<90 \mathrm{~mL} / \mathrm{min}$
e) GFR $<120 \mathrm{~mL} / \mathrm{min}$

\section{Question 4}

Which of the following drugs can cause long-lasting bone marrow toxicity four to six weeks after it is given to a patient with renal insufficiency?
a) Methotrexate
b) Hydroxychloroquine
c) Colchicine
d) Leflunomide
e) Levomethadone

\section{Question 5}

Which of the following drugs is unsuitable for the treatment of comorbidity in patients with renal insufficiency?
a) Captopril
b) Bicarbonate
c) Calcitriol
d) Diclofenac
e) Phosphate binders

\section{Question 6}

Which of the following variables is linearly related to the GFR?
a) Serum creatinine concentration
b) Elimination rate constant
c) Half-life
d) Non-renally eliminated fraction $Q_{0}$
e) Threshold concentration $\mathrm{CE}_{05}$

\section{Question 7}

Which of the following anti-infective drugs exerts its effect in timedependent fashion?
a) Gentamicin
b) Cefazolin
c) Fluoroquinolone
d) Levofloxacin
e) Ciprofloxacin

\section{Question 8}

Which of the following drugs must be given at a higher dose than normal in the setting of renal insufficiency?
a) Atenolol
b) Enoxaparin
c) Etoposide
d) Furosemide
e) Gabapentin

Question 9

The threshold concentration produces what percentage of the maximal effect?
a) $5 \%$
b) $20 \%$
c) $35 \%$
d) $50 \%$
e) $75 \%$

Question 10

How must the dosage of ciprofloxacin be adjusted in a patient with renal insufficiency if the half-life of the drug is doubled?
a) The dose should be halved.
b) The interval between doses should be doubled.
c) The drug concentration should be monitored.
d) The dose of the drug should be gradually increased.
e) The duration of therapy should be doubled. 


\title{
Drug Therapy in Patients With Chronic Renal Failure
}

\author{
Bertram Hartmann, David Czock, Frieder Keller
}

\section{eReferences}

e1. Levey AS, Stevens LA, Schmid CH, et al.: CKD-EPI (Chronic Kidney Disease Epidemiology Collaboration): A new equation to estimate glomerular filtration rate. Ann Intern Med 2009; 150: 604-12.

e2. Schou M, Kampf D: Lithium and the kidneys. In: Bauer M, Grof P, Mueller-Oerlinghausen B (eds.): Lithium in Neuropsychiatry. The comprehensive guide. London Infarma Healthcare 2006: 251-8

e3. Rabkin R, Ryan MP, Duckworth WC: The renal metabolism of insulin. Diabetologia 1984; 27: 351-7.

e4. Drüeke TB, Locatelli F, Clyne N, et al.: CREATE Investigators: Normalization of hemoglobin level in patients with chronic kidney -disease and anemia. N Engl J Med 2006; 355: 2071-84.

e5. Singh AK, Szczech L, Tang KL, et al.: CHOIR Investigators: Correction of anemia with epoetin alfa in chronic kidney disease. N Engl J Med 2006; 355: 2085-98.

e6. Pfeffer MA, Burdmann EA, Chen CY, et al.: TREAT Investigators: A trial of darbepoetin alfa in type 2 diabetes and chronic kidney -disease. N Engl J Med 2009; 361: 2019-32.

e7. Tonelli M, Pannu N, Manns B: Oral phosphate binders in patients with kidney failure. N Engl J Med 2010; 362: 1312-24.

e8. Kunin CM, Rees SB, Merrill JP, Finland M: Persistence of antibiotics in blood of patients with acute renal failure. I. Tetracycline and chlortetracycline. J Clin Invest 1959; 38: 1487-97.

e9. Dost FH: Die Clearance. Klin Wochenschr 1949, 27: 257-64.

e10. Dettli L: Drug dosage in renal disease. Clin Pharmacokinet. 1976; 1: 126-34.

e11. Augsberger A: Quantitatives zur Therapie mit Herzglykosiden. II. Mitteilung. Kumulation und Abklingen der Wirkung. Klin Wochenschr 1954; 32: 945-51.

e12. Kunin CM: A guide to use of antibiotics in patients with renal disease. A table of recommended doses and factors governing serum levels. Ann Intern Med 1967; 67: 151-8. e13. Gurwitz JH: Start low and go slow: dosing of antipsychotic medications in elderly patients with dementia. Arch Intern Med 1995; 155: 2017-8.

e14. Ehrlich P: Address in pathology on chemotherapeutics: Scientific principles, methods, and results. Lancet 1913; 4694: 445-51.

e15. Uhlig K, Macleod A, Craig J, et al.: Grading evidence and recommendations for clinical practice guidelines in nephrology. A position statement from Kidney Disease: Improving Global Outcomes (KDIGO). Kidney Int 2006; 70: 2058-65.

e16. Chennavasin P, Brater DC: Nomograms for drug use in renal disease. Clin Pharmacokinet. 1981; 6: 193-214.

e17. Segura J, Ruilope LM: Should diuretics always be included as initial antihypertensive management in early-stage CKD? Curr Opin Nephrol Hypertens 2009; 18: 392-6.

e18. Strippoli GF, Navaneethan SD, Craig JC: Haemoglobin and haematocrit targets for the anaemia of chronic kidney disease. Cochrane Database Syst Rev. 2006; 4: CD003967.

e19. Rozen-Zvi B, Gafter-Gvili A, Paul M, Leibovici L, Shpilberg O, Gafter U: Intravenous versus oral iron supplementation for the treatment of anemia in CKD: systematic review and metaanalysis. Am J Kidney Dis 2008; 52: 897-906.

e20. Palmer SC, McGregor D0, Craig JC, Elder G, Macaskill P, Strippoli GF: Vitamin D compounds for people with chronic kidney disease not requiring dialysis. Cochrane Database Syst Rev. 2009; 4: CD008175.

e21. Strippoli GF, Tong A, Palmer SC, Elder G, Craig JC: Calcimimetics for secondary hyperparathyroidism in chronic kidney disease patients. Cochrane Database Syst Rev. 2006; 4: CD006254.

e22. Roderick P, Willis NS, Blakeley S, Jones C, Tomson C: Correction of chronic metabolic acidosis for chronic kidney disease patients. Cochrane Database Syst Rev. 2007; 1: CD001890.

e23. Navaneethan SD, Palmer SC, Craig JC, Elder GJ, Strippoli GF: Benefits and harms of phosphate binders in CKD: a systematic review of randomized controlled trials. Am J Kidney Dis 2009; 54: 619-37. 


\title{
Drug Therapy in Patients With Chronic Renal Failure
}

\author{
Bertram Hartmann, David Czock, Frieder Keller
}

\section{Case Illustration}

A 33-year-old woman is admitted to hospital in preparation for peritoneal dialysis and implantation of a Tenckhoff catheter. She suffers from chronic transplant failure 12 years after renal transplantation. She developed end-stage renal failure at age 19 because of focal segmental glomerulosclerosis.

10 months ago, she underwent a biopsy of the transplanted kidney, which revealed interstitial fibrosis with tubular atrophy and calcineurin-inhibitor damage. The serum creatinine was 1220 micromoles/L, corresponding to a GFR of $5.7 \mathrm{~mL} / \mathrm{min}$. There were no other important laboratory abnormalities. She categorically refused hemodialysis, the creation of a dialysis fistula, or the implantation of a Shaldon catheter.

Her general condition is surprisingly good; indeed, she is asymptomatic except for labial herpes (Figure).

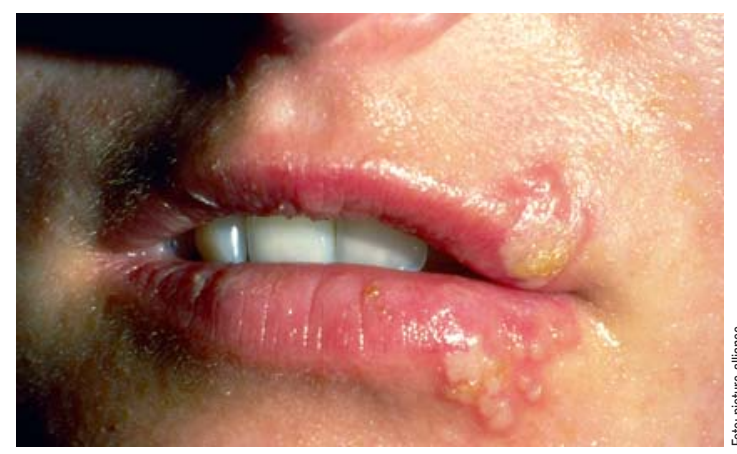

Figure: Herpes labialis
She weighs $59 \mathrm{~kg}$ and is $170 \mathrm{~cm}$ tall. The systolic blood pressure is $130 \mathrm{mmHg}$ and the pulse $72 / \mathrm{min}$. The heart, lungs, abdomen, and limbs are all unremarkable on examination. Her current medications are prednisolone, mycophenolate, and sirolimus.

The surgeons and anesthetists are ready to implant a Tenckhoff catheter, but the patient's labial herpes must be treated first with an antiviral drug. She refuses IV drug therapy and is therefore given valacyclovir by mouth. The normal dosage is two 500-mg tablets taken three times daily.

\section{What dose would you have given?}

The authors gave valganciclovir in a reduced dose, a single 500-mg tablet taken twice daily. This adjusted dose was still twice as high as the dose recommended in our tables, namely, 500 mg once daily (4). Today, we would give brivudine instead, in a single daily dose of $125 \mathrm{mg}$, as this drug is converted outside the kidneys to its inactive metabolite bromovinyluracil.

Labial herpes resolved completely within 48 hours, whereupon the patient was transferred to the surgery ward and operated on under a brief general anesthetic the next day. Two days after surgery, we were called to see the patient because she could not speak and could only sit up with difficulty. We suspected a neurotoxic adverse effect of valaciclovir and reassured the patient that her condition would improve within 24 hours. Valaciclovir was stopped and her neurotoxic manifestations promptly resolved. 